\title{
Antioxidant and cytoprotective effects of morin against hydrogen peroxide-induced oxidative stress are associated with the induction of Nrf-2-mediated HO-1 expression in V79-4 Chinese hamster lung fibroblasts
}

\author{
MOON HEE LEE ${ }^{1 *}$, HEE-JAE CHA $^{2 *}$, EUN OK CHOI $^{1}$, MIN HO HAN $^{3}$, \\ SUNG OK KIM ${ }^{4}$, GI-YOUNG KIM ${ }^{5}$, SU HYUN HONG ${ }^{6}$, CHEOL PARK $^{7}$, SUNG-KWON MOON ${ }^{8}$, \\ SOON-JEONG JEONG ${ }^{9}$, MOON-JIN JEONG ${ }^{10}$, WUN-JAE KIM ${ }^{11}$ and YUNG HYUN CHOI ${ }^{1,6}$
}

${ }^{1}$ Anti-Aging Research Center, Dongeui University, Busan 614-714; ${ }^{2}$ Department of Parasitology and Genetics, Kosin University, College of Medicine, Busan 602-702; ${ }^{3}$ Natural Products Research Team, Marine Biodiversity Institute of Korea,

Seocheon 325-902; ${ }^{4}$ Department of Food Science and Biotechnology, College of Engineering, Kyungsung University, Busan 608-736; ${ }^{5}$ Laboratory of Immunobiology, Department of Marine Life Sciences, Jeju National University, Jeju 690-756; ${ }^{6}$ Department of Biochemistry, Dongeui University College of Korean Medicine, Busan 614-052; ${ }^{7}$ Department of Molecular Biology, College of Natural Sciences and Human Ecology, Dongeui University, Busan 614-714; ${ }^{8}$ School of Food Science and Technology, Chung-Ang University, Anseong 456-756; ${ }^{9}$ Department of Dental Hygiene, College of Health Sciences, Youngsan University, Yangsan 626-790; ${ }^{10}$ Department of Oral Histology and Developmental Biology, School of Dentistry,

Chosun University, Gwangju 501-759; ${ }^{11}$ Department of Urology, Chungbuk National University,

College of Medicine and Institute for Tumor Research, Cheongju 362-763, Republic of Korea

Received September 20, 2016; Accepted January 16, 2017

DOI: $10.3892 / \mathrm{ijmm} .2017 .2871$

\begin{abstract}
Natural phytochemicals of plant origin, including flavonoids, have been found to be potent antioxidants providing beneficial effects against oxidative stress-related diseases. The present study was carried out to investigate the antioxidant properties of morin, a flavonoid originally isolated from the flowering plants of the Moraceae family. Superoxide dismutase (SOD)-like activity and 2,2'-azino-bis-(3-ethylbenzothiazoline-6-sulfonic acid) (ABTS ${ }^{\bullet}$ ) radical scavenging activity were determined. We also investigated the cytoprotective effects of morin against hydrogen peroxide $\left(\mathrm{H}_{2} \mathrm{O}_{2}\right)$-induced DNA damage and apoptosis in V79-4 Chinese hamster lung fibroblasts. Our
\end{abstract}

Correspondence to: Professor Wun-Jae Kim, Department of Urology, Chungbuk National University, College of Medicine and Institute for Tumor Research, 7761 Sunhwan-ro, Seowon-gu, Cheongju 362-763, Republic of Korea

E-mail:wjkim@chungbuk.ac.kr

Professor Yung Hyun Choi, Department of Biochemistry, Dongeui University College of Korean Medicine, 52-57 Yangjeong-ro, Busanjin, Busan 614-052, Republic of Korea

E-mail: choiyh@deu.ac.kr

*Contributed equally

Key words: morin, antioxidant, apoptosis, reactive oxygen species, Nrf2/HO-1 results demonstrated that morin had strong scavenging effects against $\mathrm{ABTS}^{\bullet+}$ radicals with enhanced SOD activity, which varied in a dose-dependent manner. Morin was found to reduce $\mathrm{H}_{2} \mathrm{O}_{2}$-induced intracellular reactive oxygen species generation and nuclear DNA damage, and it recovered cell viability damaged by $\mathrm{H}_{2} \mathrm{O}_{2}$ via inhibition of mitochondrial dysfunction-mediated apoptosis. Notably, the treatment of V79-4 cells with morin markedly enhanced the expression of heme oxygenase-1 (HO-1) but not quinone oxidoreductase-1, which was associated with the increased expression and phosphorylation of nuclear factor-erythroid 2-related factor 2 (Nrf2) and the downregulation of Kelch-like ECH-associated protein 1 expression. Based on our findings, we conclude that morin effectively ameliorated oxidative stress-induced DNA damage through intrinsic free radical scavenging activity and activation of the Nrf2/HO-1 pathway.

\section{Introduction}

Oxidative stress reflects an imbalance between the production of reactive oxygen species (ROS) and the biological system's ability to remove them $(1,2)$. Although some ROS act as cellular messengers in redox signaling, excessive ROS can arbitrarily react with all components of the cell, including proteins, lipids and DNA, thereby causing oxidative stress and damage in these macromolecules $(3,4)$. This damage is a crucial etiological factor that is implicated in various human diseases, including aging and cancer, as well as neurodegenerative and chronic diseases $(5,6)$. Therefore, the development of safe and effective antioxidants continues to be an important research target $(7,8)$. 
The antioxidant activity of natural compounds isolated from plants has been reported to counteract free radicals $(9,10)$. Among such compounds, flavonoids, a family of well-known polyphenols, are bioactive compounds, which are widespread in plants and have long received attention in the development of antioxidants $(8,11,12)$. Morin $\left(2^{\prime}, 3,4 ', 5,7\right.$-pentahydroxyflavone), a member of the flavonoid family, is a yellow-colored compound that can be isolated from members of the Moraceae family, which are used as herbal medicines (13-15). Morin exhibits certain biological activities, which include antioxidant (16-18), cytoprotection $(19,20)$, antidiabetic $(21,22)$, anti-inflammatory (23-25) and anticancer properties (26-29). Moreover, morin has been reported to possess cellular protective effects against oxidative stress-induced damage through activation of the nuclear factor-erythroid 2-related factor 2 (Nrf2) signaling pathway (30-32). However, the mechanism underlying the action of morin against oxidative stress has not been fully studied to date.

In the present study, the antioxidant activities of morin were examined through a series of in vitro tests that were conducted to examine its superoxide dismutase (SOD)-like and 2,2'-azino-bis-(3-ethylbenzothiazoline-6-sulfonic acid) $\left(\mathrm{ABTS}^{\cdot+}\right)$ free radical scavenging activities. We also investigated the ameliorative effects of morin on cell damage induced by hydrogen peroxide $\left(\mathrm{H}_{2} \mathrm{O}_{2}\right)$ in V79-4 Chinese hamster lung fibroblasts and the possible mechanism underlying this cytoprotective effect.

\section{Materials and methods}

Reagents and antibodies. Dulbecco's modified Eagle's medium (DMEM), fetal calf serum (FCS), streptomycin, and penicillin were purchased from WelGENE Inc. (Daegu, Republic of Korea). Morin, 3-(4,5-dimethylthiazol-2-yl]-2,5-diphenyltetrazolium bromide (MTT), 4',6-diamidino-2-phenylindole (DAPI), $N$-acetyl-L-cysteine (NAC), 6,6'-tetrachloro-1,1',3,3'-tetraethyl-imidacarbocyanine iodide (JC-1) and zinc protoporphyrin IX (ZnPP), a specific inhibitor of heme oxygenase-1 (HO-1), were obtained from Sigma-Aldrich Chemical Co. (St. Louis, MO, USA). A SOD assay kit was obtained from Dojindo Molecular Technologies (Tokyo, Japan). 2',7'-Dichlorodihydrofluorescein diacetate (DCF-DA) and a fluorescein-conjugated Annexin V (Annexin V-FITC) staining assay kit were purchased from Molecular Probes (Eugene, OR, USA) and BD Biosciences (San Jose, CA, USA), respectively. An enhanced chemiluminescence (ECL) detection system was purchased from Amersham Co. (Arlington Heights, IL, USA). Primary antibodies (Table I) were purchased from Santa Cruz Biotechnology, Inc. (Dallas, TX, USA), Cell Signaling Technology, Inc. (Danvers, MA, USA) and Abcam, Inc. (Cambridge, MA, USA). Horseradish (HRP)-conjugated secondary antibodies were obtained from Amersham Co. Morin was dissolved in dimethyl sulphoxide (DMSO; Sigma-Aldrich Chemical Co.) and then diluted with medium to the desired concentration prior to use. The final DMSO concentration was $<0.1 \%$ in all experiments. All other chemicals were purchased from Sigma-Aldrich Chemical Co.

Measurement of SOD-like activity. The SOD-like activity of morin was measured using a SOD assay kit according to the manufacturer's instructions. Briefly, $20 \mu \mathrm{l}$ of morin stock solution was added to $200 \mu \mathrm{l}$ of the working solution in the SOD assay kit. The mixture was incubated at $37^{\circ} \mathrm{C}$ for $20 \mathrm{~min}$ after gentle shaking and then $20 \mu \mathrm{l}$ of the kit enzyme working solution was added. The absorbance of the mixtures was measured at $450 \mathrm{~nm}$ using an enzyme-linked immunosorbent assay (ELISA) reader (Molecular Devices, Sunnyvale, CA, USA), and the SOD activity was calculated according to the manufacturer's instructions (33). Vitamin C was used as a positive control.

Measurement of ABTS radical scavenging activity. The ABTS assay was based on a previously described method (34) with slight modifications. ABTS radical cation $\left(\mathrm{ABTS}^{\circ+}\right)$ was produced by the reaction of a $7 \mathrm{mM}$ ABTS solution with potassium persulphate $(2.45 \mathrm{mM})$. The ABTS $^{\cdot+}$ solution was diluted with ethanol to an absorbance of $0.70 \pm 0.05$ at $734 \mathrm{~nm}$. The mixture was stored in the dark at room temperature for $12 \mathrm{~h}$ before use. After the addition of $25 \mu \mathrm{l}$ of morin solution or vitamin $\mathrm{C}$ as a positive control to $2 \mathrm{ml}$ of diluted $\mathrm{ABTS}^{\cdot+}$ solution, absorbance was measured at $734 \mathrm{~nm}$ after exactly $6 \mathrm{~min}$. Inhibition of the ABTS radical by morin was calculated using the formula: ABTS scavenging activity $(\%)=[1-($ absorbance of the sample/absorbance of the control)] x 100.

Cell culture. The Chinese hamster lung fibroblast V79-4 cell line was obtained from the American Type Culture Collection (ATCC; Manassas, MD, USA) and cultured in DMEM containing $10 \%$ heat-inactivated FCS, streptomycin $(100 \mu \mathrm{g} / \mathrm{ml})$ and penicillin (100 Units $/ \mathrm{ml})$. The cells were maintained at $37^{\circ} \mathrm{C}$ in an incubator with a humidified atmosphere of $5 \% \mathrm{CO}_{2}$.

MTT assay. For the cell viability assay, V79-4 cells were seeded at $1 \times 10^{5}$ cells $/ \mathrm{ml}$ in a 96 -well plate and cultured for $24 \mathrm{~h}$ before being treated with the indicated concentrations of morin for $24 \mathrm{~h}$ in the presence or absence of $1 \mathrm{mM} \mathrm{H}_{2} \mathrm{O}_{2}$ with or without $1 \mathrm{~h}$ pretreatment of morin or NAC. After the treatments, the MTT solution $(0.5 \mathrm{mg} / \mathrm{ml})$ was added, followed by a 2-h incubation at $37^{\circ} \mathrm{C}$ in the dark, after which the medium was removed. The formazan precipitate was dissolved in DMSO. The absorbance of the formazan product was measured at $540 \mathrm{~nm}$ using an ELISA reader (35).

Nuclear staining with DAPI. The cells were harvested, washed with PBS, and fixed with $3.7 \%$ paraformaldehyde for $30 \mathrm{~min}$ at room temperature. After washing twice with PBS, the cells were attached on glass slides using cytospin (Shandon, Pittsburgh, PA, USA) and stained with $2.5 \mu \mathrm{g} / \mathrm{ml}$ DAPI solution for $20 \mathrm{~min}$ at room temperature. The stained cells were washed twice with PBS and then analyzed using a fluorescence microscope (Carl Zeiss, Deisenhofen, Germany).

Determination of apoptotic cells by flow cytometry. To assess the induced cell apoptosis rate quantitatively, the cells were washed with PBS and stained with $5 \mu$ l of Annexin V-FITC and $5 \mu \mathrm{l}$ of propidium iodide (PI) in each sample according to the manufacturer's protocols. After a 15-min incubation at room temperature in the dark, the degree of apoptosis was quantified as a percentage of the Annexin V-positive and PI-negative (Annexin $\mathrm{V}^{+} / \mathrm{PI}^{-}$cells) cells using a flow cytometer (BD Biosciences). 
Table I. Antibodies used in the present study.

\begin{tabular}{llll}
\hline Antibody & \multicolumn{1}{c}{ Origin } & \multicolumn{1}{c}{ Company } & Cat. no. \\
\hline Actin & Mouse monoclonal & Santa Cruz Biotechnology, Inc. & SC-47778 \\
Caspase-3 & Mouse monoclonal & Santa Cruz Biotechnology, Inc. & SC-7272 \\
PARP & Rabbit polyclonal & Santa Cruz Biotechnology, Inc. & SC-7150 \\
p- $\gamma$ H2AX & Rabbit monoclonal & Cell Signaling Technology, Inc. & 9718 \\
$\gamma \mathrm{H} 2 \mathrm{AX}$ & Rabbit monoclonal & Cell Signaling Technology, Inc. & 7631 \\
p-Nrf2 & Rabbit monoclonal & Abcam, Inc. & ab76026 \\
Nrf2 & Rabbit polyclonal & Santa Cruz Biotechnology, Inc. & SC-13032 \\
Keap1 & Goat polyclonal & Santa Cruz Biotechnology, Inc. & SC-10789 \\
HO-1 & Rabbit polyclonal & Santa Cruz Biotechnology, Inc. & SC-16464 \\
NQO1 & Goat polyclonal & Santa Cruz Biotechnology, Inc. & \\
\hline
\end{tabular}

Measurement of intracellular ROS. The oxidation-sensitive dye DCF-DA was used to determine the formation of intracellular ROS. Briefly, the cells from each treatment were harvested, washed twice with PBS, and then re-suspended in $10 \mu \mathrm{M}$ DCF-DA for $30 \mathrm{~min}$ at $37^{\circ} \mathrm{C}$ in the dark. The production of ROS in the cells was monitored immediately using a flow cytometer (36).

Measurement of mitochondrial membrane potential $(M M P, \Delta \psi m)$. The MMP values were determined using the dual-emission potential-sensitive probe JC-1. Briefly, the cells were collected and incubated with $10 \mu \mathrm{M}$ of JC-1 for $20 \mathrm{~min}$ at $37^{\circ} \mathrm{C}$ in the dark. After the JC-1 was removed, the cells were washed with PBS to remove the unbound dye, and the amount of JC- 1 retained by 10,000 cells per sample was measured by using a flow cytometer (37).

Determination of DNA damage by comet assay. After each treatment, the cells were washed with PBS, and the cell suspension was mixed with $0.5 \%$ low melting agarose (LMA) at $37^{\circ} \mathrm{C}$ before adding it to the slides precoated with $1.0 \%$ normal melting agarose. After the agarose was solidified, the slides were covered with another $0.5 \%$ LMA and then immersed in lysis buffer [2.5 M NaCl, $500 \mathrm{mM}$ Na-ethylenediaminetetraacetic acid (EDTA), $1 \mathrm{M}$ Tris buffer, $1 \%$ sodium lauroyl sarcosinate and $1 \%$ Triton $\mathrm{X}-100$ ] for $1 \mathrm{~h}$ at $4^{\circ} \mathrm{C}$. The slides were later transferred into an unwinding buffer for another $20 \mathrm{~min}$ for DNA unwinding. The slides were then placed in an electrophoresis tank containing $300 \mathrm{mM} \mathrm{NaOH}$ and $1 \mathrm{mM}$ Na-EDTA (pH 13.0). An electrical field was then applied (300 mA, $25 \mathrm{~V}$ ) for $20 \mathrm{~min}$ at $25^{\circ} \mathrm{C}$ to draw the negatively charged DNA toward the anode. The slides were washed three times for $5 \mathrm{~min}$ at $25^{\circ} \mathrm{C}$ in a neutralizing buffer ( $0.4 \mathrm{M}$ Tris, $\mathrm{pH} 7.5$ ), and then stained with $20 \mu \mathrm{g} / \mathrm{ml}$ PI. The slides were examined under a fluorescence microscope.

Protein extraction and western blot analysis. All cell lysates were lysed in an extraction buffer [ $25 \mathrm{mM}$ Tris- $\mathrm{Cl}(\mathrm{pH} 7.5)$, $250 \mathrm{mM} \mathrm{NaCl}, 5 \mathrm{mM}$ EDTA, $1 \%$ Nonidet P-40, $0.1 \mathrm{mM}$ sodium orthovanadate, $2 \mu \mathrm{g} / \mathrm{ml}$ leupeptin, and $100 \mu \mathrm{g} / \mathrm{ml}$ phenylmethylsulfonyl fluoride]. The protein concentration in the cell lysate was determined using a detergent-compatible protein assay from Bio-Rad (Hercules, CA, USA). In the Western blot analysis, equal amounts of protein (30-50 $\mu \mathrm{g})$ were separated by $8-10 \%$ sodium dodecyl sulfate-polyacrylamide gel electrophoresis (SDS-PAGE) and then were electro-transferred to polyvinylidene fluoride (PVDF) membranes (Schleicher \& Schuell, Keene, NH, USA). The membranes were blocked with $5 \%$ skim milk for $1 \mathrm{~h}$ and then subjected to immunoblot analysis with the appropriate antibodies. Using an ECL detection system, immunoreactive bands were detected and exposed to X-ray film.

HO-1 activity assay. HO-1 enzyme activity was measured as previously described (38). In brief, lysates of the cells were prepared, and homogenates containing biliverdin reductase were obtained from rat liver. After quantifying the protein concentration, the cell lysates and homogenates were incubated with nicotinamide adenine dinucleotide phosphate (NADPH) and hemin for $1 \mathrm{~h}$, whereas the blank samples were incubated with hemin only. The concentration of bilirubin, which was the product of degradation by HO-1, was determined as the difference in absorbance at 464 and $530 \mathrm{~nm}$ using an ELISA plate reader. HO-1 activity was expressed as picomoles of bilirubin per milligram of protein.

Statistical analysis. All experiments were conducted in triplicate $(n=3)$, and a one-way ANOVA (SPSS 11.5 statistical software; SPSS, Inc., Chicago, IL, USA) was used to compare the mean values of each treatment. Significant differences were determined using Duncan's test. $\mathrm{P}<0.05$ was considered to indicate a statistically significant difference.

\section{Results}

Antioxidant activity of morin. To determine the antioxidant activity of morin, the SOD-like enzyme and ABTS radical scavenging activities were evaluated. As shown in Fig. 1A, the SOD-like enzyme activity of morin was highly increased in a concentration-dependent manner to the given concentration. For example, the percentage of SOD-like enzyme activity was $\sim 72 \%$ at a concentration of $100 \mu \mathrm{M}$ morin, which was very similar after treatment with the same concentration of vitamin $\mathrm{C}$ used as a positive control. Similar to SOD-like enzyme activity, at different concentrations (10-1,000 $\mu \mathrm{M})$, morin was also found to effectively scavenge $\mathrm{ABTS}^{\bullet+}$ (Fig. 1B). 
A

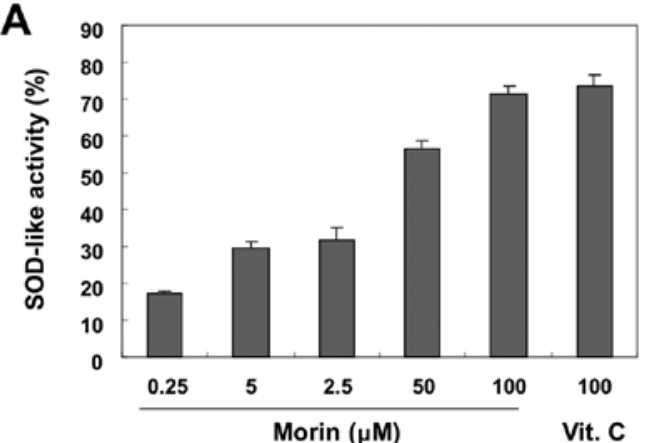

B

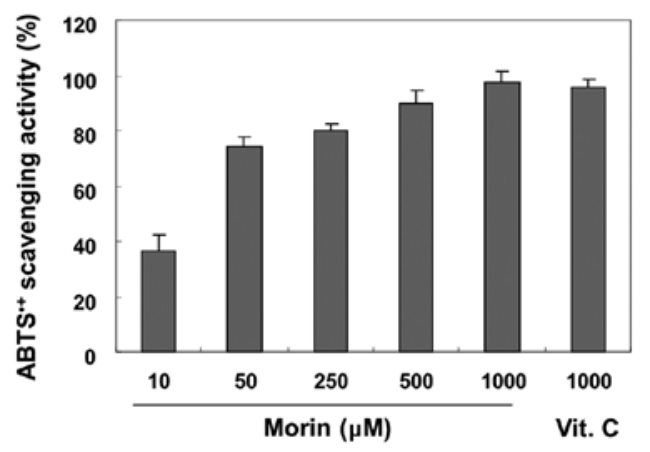

Figure 1. (A) Superoxide dismutase SOD-like and (B) ABTS radical scavenging activities of morin in comparison with vitamin $C$ (Vit. C). Values are expressed as the mean \pm standard deviation of three replicates.
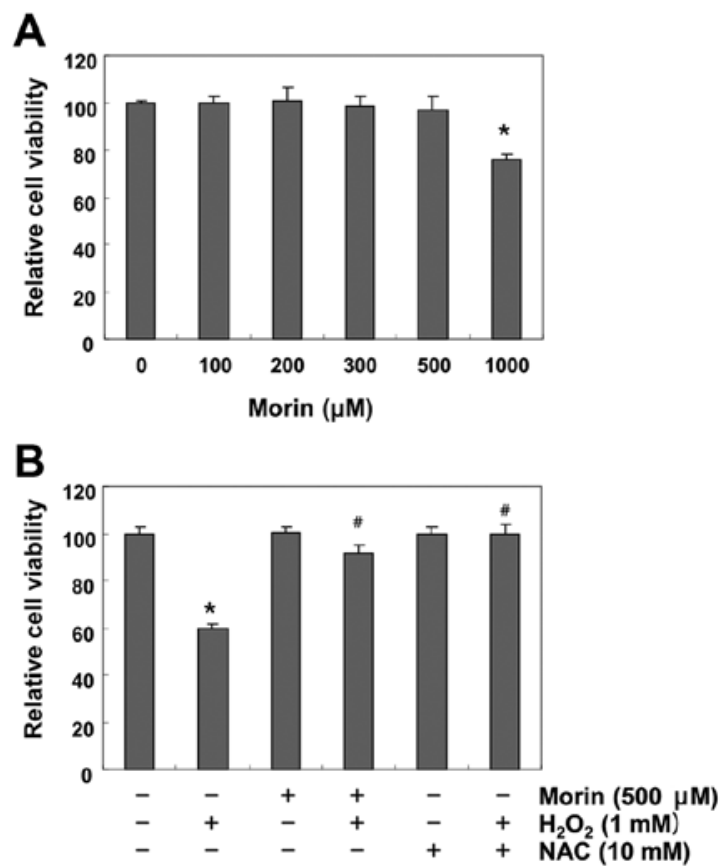

Figure 2. Effects of morin on the cell viability and $\mathrm{H}_{2} \mathrm{O}_{2}$-induced growth inhibition of V79-4 lung fibroblasts. The cells were treated with (A) various concentrations of morin for $24 \mathrm{~h}$ or (B) pretreated with $500 \mu \mathrm{M}$ morin or $10 \mathrm{mM} \mathrm{NAC}$ for $1 \mathrm{~h}$ and then incubated with or without $1 \mathrm{mM} \mathrm{H}_{2} \mathrm{O}_{2}$ for $24 \mathrm{~h}$. Cell viability was assessed using an MTT reduction assay. The results are presented as the mean \pm standard deviation values obtained from three independent experiments ( $\mathrm{P}<0.05$ compared with the control group; ${ }^{*} \mathrm{P}<0.05$ compared with the $\mathrm{H}_{2} \mathrm{O}$-treated group).

Morin protects against $\mathrm{H}_{2} \mathrm{O}_{2}$-induced inhibition of cell viability in V79-4 fibroblasts. To exclude the cytotoxicity
A
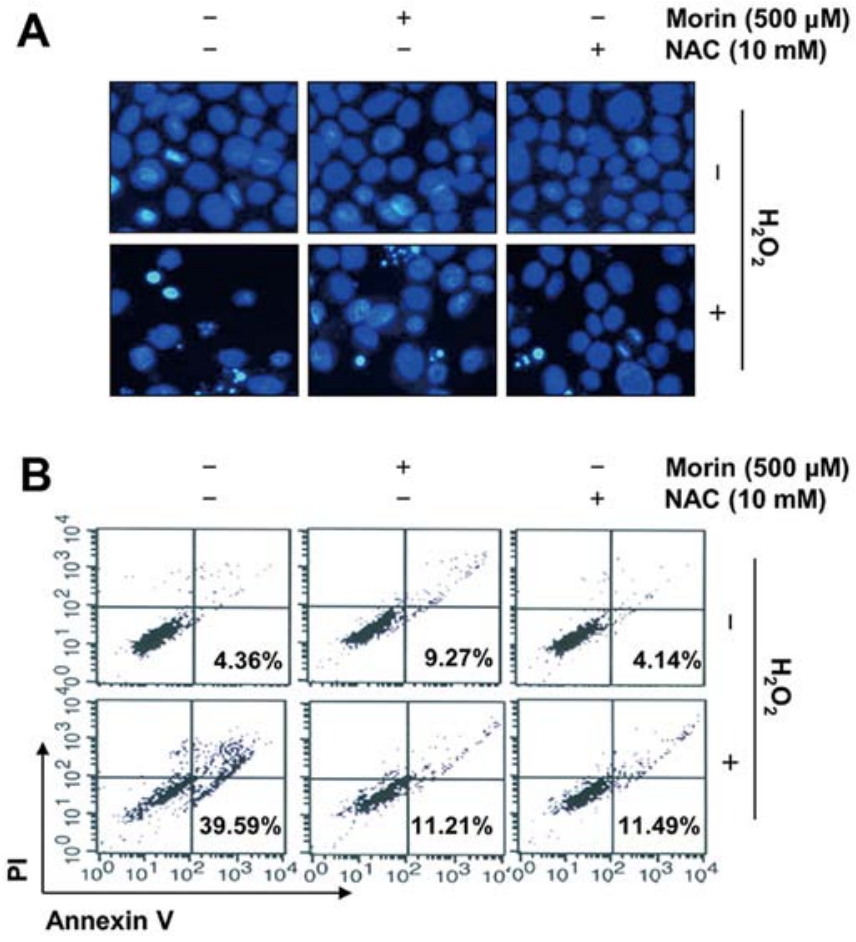

Figure 3. Protection against $\mathrm{H}_{2} \mathrm{O}_{2}$-induced apoptosis by treatment of V79-4 lung fibroblasts with morin. Cells were pretreated with $500 \mu \mathrm{M}$ morin or $10 \mathrm{mM} \mathrm{NAC}$ for $1 \mathrm{~h}$ and then incubated with or without $1 \mathrm{mM} \mathrm{H}_{2} \mathrm{O}_{2}$ for $24 \mathrm{~h}$. (A) The cells were fixed and stained with DAPI solution. The stained nuclei were observed under a fluorescence microscope ( $x 400$, original magnification). (B) To quantify the degree of apoptosis, the cells were stained with Annexin V-FITC and PI, and the percentages of apoptotic cells (Annexin $\mathrm{V}^{+} / \mathrm{PI}^{-}$cells) were then analyzed using flow cytometric analysis. The data shown represent the mean values found in two different experiments. NAC, $N$-acetyl-L-cysteine; PI, propidium iodide.

caused by morin treatment in V79-4 fibroblasts, the cells were treated with different concentrations (100-1,000 $\mu \mathrm{M})$ of morin for $24 \mathrm{~h}$. The MTT assay indicated that the treatments did not result in any cytotoxic effect at the concentration of $500 \mu \mathrm{M}$, and cell viability was significantly decreased at concentrations higher than $1,000 \mu \mathrm{M}$ (Fig. 2A). Therefore, $500 \mu \mathrm{M}$ morin was selected for use in the subsequent examination of the protective effect of morin on $\mathrm{H}_{2} \mathrm{O}_{2}$-induced cytotoxicity. A further MTT assay revealed that treatment with $1 \mathrm{mM} \mathrm{H}_{2} \mathrm{O}_{2}$ significantly reduced cell viability. However, the $\mathrm{H}_{2} \mathrm{O}_{2}$-induced reduction in cell viability was effectively protected by pretreatment with both $500 \mu \mathrm{M}$ morin and $10 \mathrm{mM}$ NAC (Fig. 2B).

Morin attenuates $\mathrm{H}_{2} \mathrm{O}_{2}$-induced apoptosis in V79-4 fibroblasts. To elucidate the cytoprotective effect of morin against the $\mathrm{H}_{2} \mathrm{O}_{2}$-induced reduction in V79-4 cell viability, we investigated the effects of morin on $\mathrm{H}_{2} \mathrm{O}_{2}$-mediated apoptosis. The results of the DAPI staining showed that treatment with $\mathrm{H}_{2} \mathrm{O}_{2}$ alone significantly increased the number of cells with condensed or blebbing nuclei. In contrast, when these cells were pretreated with morin or NAC, these phenomena were markedly reduced (Fig. 3A). The results of the flow cytometry consistently indicated that the $\mathrm{H}_{2} \mathrm{O}_{2}$ treatment enhanced the population of Annexin $\mathrm{V}^{+} / \mathrm{PI}^{-}$apoptotic cells. However, the pretreatment of cells with morin or NAC prior to exposure to $\mathrm{H}_{2} \mathrm{O}_{2}$ effectively protected the V79-4 cells against apoptosis (Fig. 3B). 

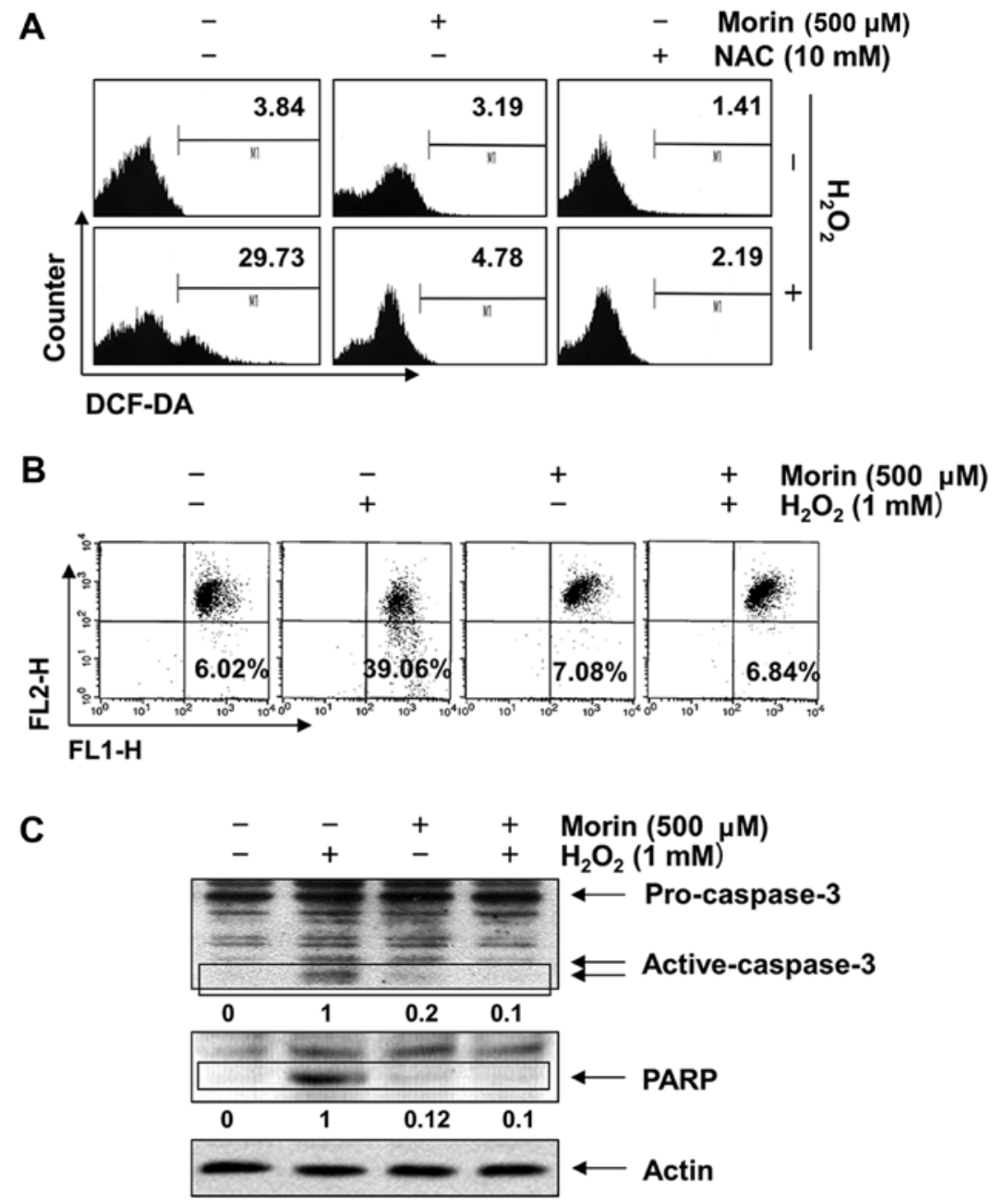

Figure 4. Inhibition of $\mathrm{H}_{2} \mathrm{O}_{2}$-induced generation of ROS, loss of MMP and activation of caspase-3 by morin in V79-4 lung fibroblasts. The cells were pretreated with $500 \mu \mathrm{M}$ morin for $1 \mathrm{~h}$ and then incubated with or without $1 \mathrm{mM} \mathrm{H}_{2} \mathrm{O}_{2}$ for (A) $1 \mathrm{~h}$ or (B and C) $24 \mathrm{~h}$. (A) To monitor ROS production, the cells were incubated at $37^{\circ} \mathrm{C}$ in the dark for 20 min with a new culture medium containing $10 \mu \mathrm{M}$ DCF-DA. ROS accumulation was measured using a flow cytometer. (B) To assess the effects of morin on the $\mathrm{H}_{2} \mathrm{O}_{2}$-induced loss of MMP, the cells were collected and incubated with $10 \mu \mathrm{M} \mathrm{JC}-1$ for 20 min at $37^{\circ} \mathrm{C}$ in the dark. The cells were then washed once with PBS and analyzed using a flow cytometer. The data shown represent the mean values from two different experiments. (C) To assess caspase-3 and PARP levels, the cells were lysed, and then equal amounts of cell lysates were separated using sodium dodecyl sulphate-polyacrylamide gel electrophoresis and transferred to PVDF membranes. The membranes were probed with anti-caspase-3 and anti-PARP antibodies, and the proteins were visualized using an ECL detection system. The relative ratios of expression as determined by the western blotting are presented at the bottom of each lane as relative values of actin expression. MMP, mitochondrial membrane potential; NAC, $N$-acetyl-L-cysteine; PVDF; polyvinylidene fluoride; PARP, poly(ADP-ribose) polymerase; ECL, enhanced chemiluminescence.

Morin suppresses $\mathrm{H}_{2} \mathrm{O}_{2}$-induced ROS generation in V79-4 fibroblasts. In a further experiment to study the mechanisms underlying the protective effect of morin, the intracellular ROS levels were determined. The results of the flow cytometric analysis using DCF-DA as a fluorescence probe demonstrated that the intensity of the DCF-liberated fluorescent signal from the $\mathrm{H}_{2} \mathrm{O}_{2}$-treated cells was markedly increased. However, the signal was effectively attenuated in the presence of morin as well as NAC (Fig. 4A).

Morin inhibits $\mathrm{H}_{2} \mathrm{O}_{2}$-induced mitochondrial dysfunction and activation of caspase-3 in V79-4 fibroblasts. The mitochondrial-mediated intrinsic apoptosis pathway is initiated by the loss of mitochondrial membrane potential (MMP, $\Delta \psi \mathrm{m}$ ) and the subsequent release of pro-apoptotic proteins, which leads to the activation of caspase- 9 and $-3(39,40)$. We therefore investigated the effects of morin on the $\mathrm{H}_{2} \mathrm{O}_{2}$-induced loss of MMP and the activation of caspase- 3 . The results indicated that the loss of MMP in $\mathrm{H}_{2} \mathrm{O}_{2}$-treated V79-4 cells increased 6.4-fold relative to the untreated control; however, the reduction in MMP was significantly inhibited by pretreatment with morin (Fig. 4B). The immunoblotting results indicated a marked increase in the level of activated caspase-3 expression in the $\mathrm{H}_{2} \mathrm{O}_{2}$-treated cells compared with the control. A subsequent increase in cleaved poly(ADP-ribose) polymerase (PARP), a well-known substrate of caspase-3 (41), was also observed. However, the results clearly showed that $\mathrm{H}_{2} \mathrm{O}_{2}$-induced caspase- 3 activation and PARP degradation were completely abrogated by pretreatment with morin (Fig. 4C).

Morin protects against $\mathrm{H}_{2} \mathrm{O}_{2}$-induced DNA damage in V79-4 fibroblasts. We then assessed the protective effects of morin against $\mathrm{H}_{2} \mathrm{O}_{2}$-induced DNA damage by applying the alkaline comet assay and Western blot analysis. The comet assay measures single- and double-strand breaks that are caused either directly by the DNA-damaging system or indirectly by 
A

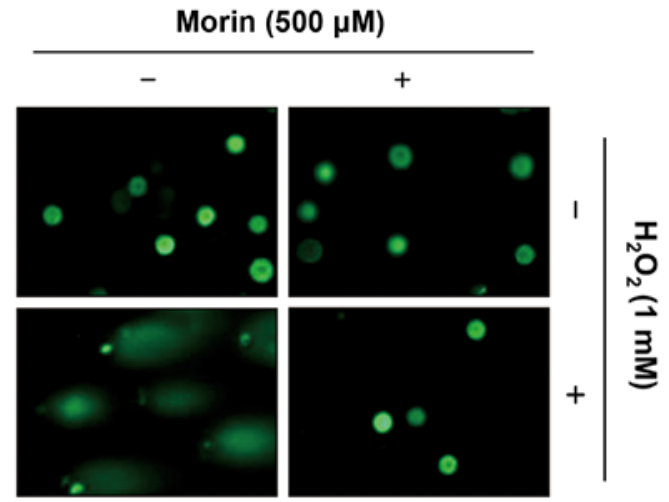

B

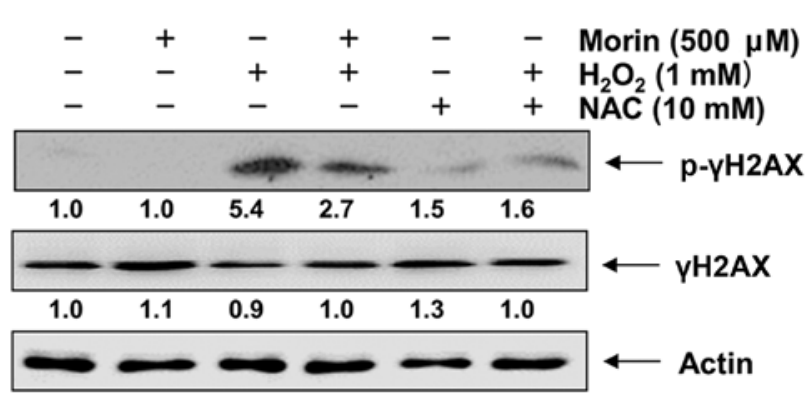

Figure 5. Inhibition of $\mathrm{H}_{2} \mathrm{O}_{2}$-induced DNA damage by morin in V79-4 lung fibroblasts. Cells were pretreated with $500 \mu \mathrm{M}$ morin or $10 \mathrm{mM} \mathrm{NAC}$ for $1 \mathrm{~h}$ and then incubated with or without $1 \mathrm{mM} \mathrm{H}_{2} \mathrm{O}_{2}$ for $24 \mathrm{~h}$. (A) To detect cellular DNA damage, the comet assay was performed and representative images of the comets were captured using a fluorescence microscope (x200, original magnification). (B) The cells were lysed and then equal amounts of cell lysates were separated on sodium dodecyl sulphate-polyacrylamide gel electrophoresis and transferred to PVDF membranes. The membranes were probed with specific antibodies against p- $\gamma \mathrm{H} 2 \mathrm{AX}, \gamma \mathrm{H} 2 \mathrm{AX}$ and actin (internal control), and the proteins were visualized using an ECL detection system. The relative ratios of expression as determined by western blotting are presented at the bottom of each lane as relative values of actin expression. NAC, $N$-acetyl-L-cysteine; PVDF, polyvinylidene fluoride; ECL, enhanced chemiluminescence.

the repair mechanism (42). As shown in Fig. 5A, the exposure of cells to $\mathrm{H}_{2} \mathrm{O}_{2}$ increased DNA breaks, resulting in an increase in fluorescence intensity in the tails of the comet-like structures. However, pretreatment with morin led to a marked decrease in damage to DNA (Fig. 5A). Furthermore, as expected, $\mathrm{H}_{2} \mathrm{O}_{2}$ enhanced the phosphorylation of histone $\lambda \mathrm{H} 2 \mathrm{AX}$ on serine 139 , which was rapidly increased after the induction of DNA double-strand breaks (43), whereas pretreatment with morin prevented the increase in the phosphorylation of histone $\lambda \mathrm{H} 2 \mathrm{AX}$ (Fig. 5B).

Morin enhances the expression Nrf2 and HO-1 in V79-4 fibroblasts. The transcription factor Nrf2 regulates the expression of antioxidant responsive element (ARE)-driven antioxidant and cytoprotective genes, including HO-1 and quinone oxidoreductase-1 (NQO-1), to control the cellular defense against oxidative stress $(44,45)$. Thus, we examined the effects of morin on the levels of Nrf2, HO-1 and NQO-1 expression, and found that treatment with morin gradually increased Nrf2 expression and its phosphorylation, but not NQO-1 expression, in a time-dependent manner. It concomitantly decreased the level of Kelch-like $\mathrm{ECH}$-associated protein 1 (Keap1), which is a negative regulator of $\mathrm{Nrf} 2$ (Fig. 6A). Morin also enhanced HO-1 expression as well as HO-1 activity in a time-dependent manner (Fig. 6B).
A

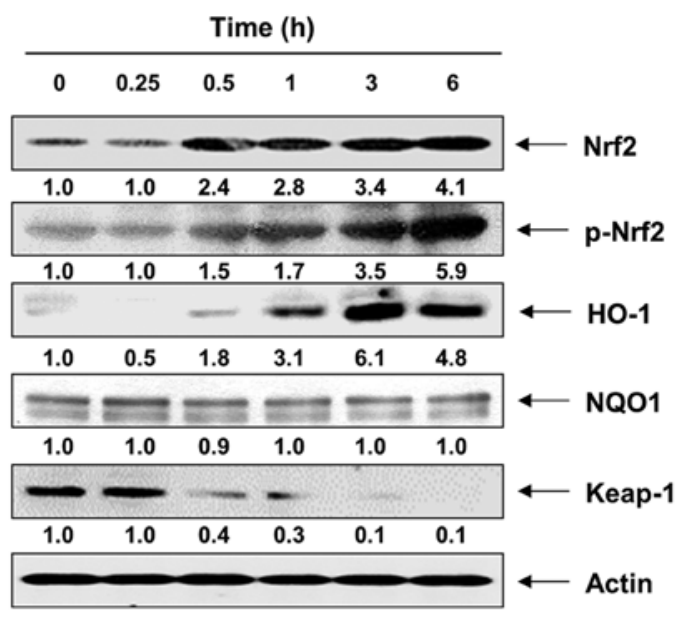

B

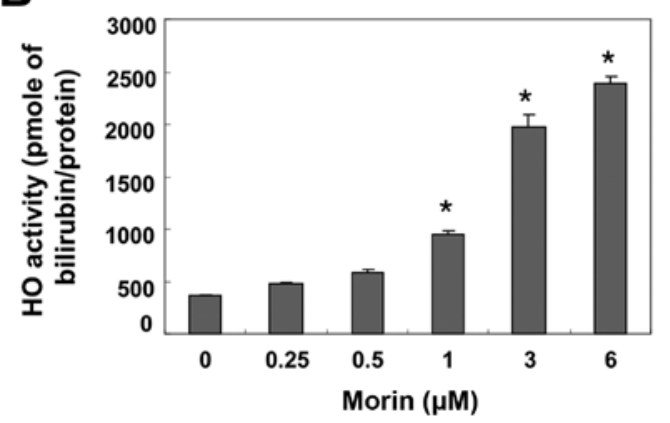

Figure 6. Effects of morin on the expression of Nrf2 signaling-related proteins and activity of HO-1 in V79-4 lung fibroblasts. (A) The cells were incubated with $500 \mu \mathrm{M}$ morin for the indicated time period. Cellular proteins were separated using sodium dodecyl sulphate-polyacrylamide gel electrophoresis and then transferred onto PVDF membranes. The membranes were probed with specific antibodies against Nrf2, p-Nrf2, HO-1, NQO-1 and Keap1. Proteins were visualized using an ECL detection system. Actin was used as an internal control. The relative ratios of expression as determine by western blotting are presented at the bottom of each lane as relative values of actin expression. (B) The HO activities of cells grown under the same conditions as (A) were determined based on bilirubin formation. Data represent the mean values from three independent experiments $\left({ }^{*} \mathrm{P}<0.05\right.$ compared with the control group). HO-1, heme oxygenase-1; Nrf2, nuclear factor-erythroid 2-related factor 2; ECL, enhanced chemiluminescence; PVDF, polyvinylidene fluoride.

The Nrf2/HO-1 pathway is involved in the protective effects of morin in $\mathrm{H}_{2} \mathrm{O}_{2}$-treated V79-4 fibroblasts. To determine whether the morin-induced antioxidant and cytoprotective activities against oxidative stress were mediated through the activation of the Nrf2/HO-1 pathway, V79-4 cells were pretreated with or without a specific inhibitor of $\mathrm{HO}-1, \mathrm{ZnPP}$, and the levels of ROS and cell viability were assessed. As shown in Fig. 7, ZnPP abrogated the protective effect of morin on the $\mathrm{H}_{2} \mathrm{O}_{2}$-induced production of ROS and the reduction in cell viability.

\section{Discussion}

Oxidative stress, represented as the increase in ROS, is an abnormal phenomenon when the production of free radicals exceeds the antioxidant capacity. Extreme increases in ROS can destroy the cytoprotective defense mechanism by the emasculation of antioxidant systems, leading to the develop- 
A

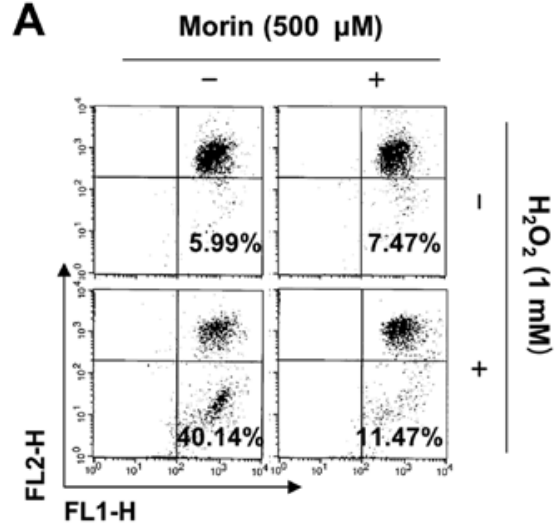

B

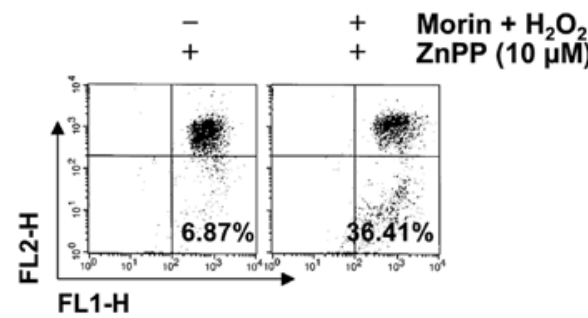

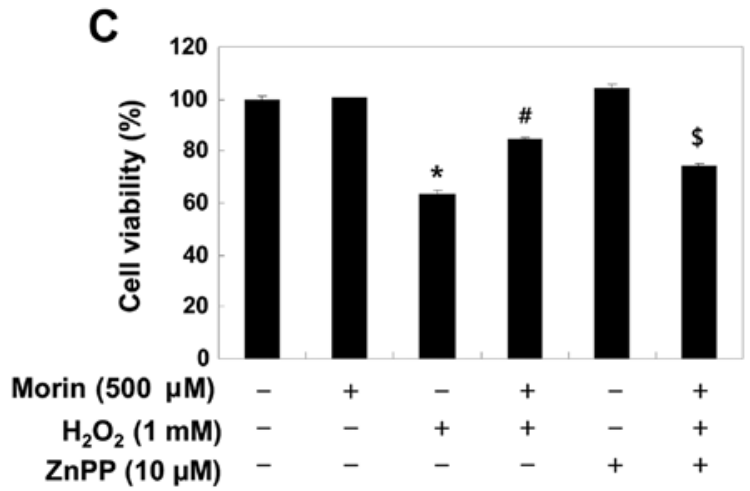

Figure 7. Effects of an HO-1 inhibitor on morin-mediated attenuation of MMP loss and growth inhibition by $\mathrm{H}_{2} \mathrm{O}_{2}$ in $\mathrm{V}^{7}-4$ lung fibroblasts. The cells were pretreated for $1 \mathrm{~h}$ with $500 \mu \mathrm{M}$ morin and then stimulated with or without $1 \mathrm{mM} \mathrm{H}_{2} \mathrm{O}_{2}$ for a further $6 \mathrm{~h}$ in the absence or presence of $10 \mu \mathrm{M}$ of $\mathrm{ZnPP}$, an $\mathrm{HO}-1$ inhibitor. (A and B) MMP was then determined. (C) Cell viability was then assessed. The results are expressed the mean \pm standard deviation of values obtained in three independent experiments $\left({ }^{*} \mathrm{P}<0.05\right.$ compared with the control group; ${ }^{\#} \mathrm{P}<0.05$ compared with the $\mathrm{H}_{2} \mathrm{O}_{2}$-treated group; ${ }^{\$} \mathrm{P}<0.05$ compared with the $\mathrm{H}_{2} \mathrm{O}_{2}$ and morin-treated group). MMP, mitochondrial membrane potential; HO-1, heme oxygenase-1.

ment of several human diseases $(5,6)$. The accumulation of ROS directly causes base modification and DNA strand breaks, resulting in DNA damage $(3,4)$. Accumulation of ROS also induces mitochondrial dysfunction, resulting in a decrease in MMP, and activation of caspase- 9 and -3 through the release of mitochondrial apoptotic factors into the cytoplasm. These factors are known to be strong stimulators of the mitochondrial-mediated intrinsic apoptosis pathway $(46,47)$. In the present study, the results showed that morin had a strong antioxidant capacity as determined by SOD-like activity and ABTS scavenging ability assays, which are widely used to analyze the antioxidant potential of candidate materials. Additional data from the MTT assay and flow cytometry demonstrated that morin significantly rescued cell viability and reduced the apoptosis caused by $\mathrm{H}_{2} \mathrm{O}_{2}$-induced oxidative stress in V79-4 lung fibroblasts. We also found that the protective effects were associated with the suppression of ROS accumulation and DNA damage, which indicates that morin may enhance the antioxidant and DNA repair systems. In addition, the results of the JC-1 staining and immunoblotting showed that morin significantly restored the $\mathrm{H}_{2} \mathrm{O}_{2}$-induced loss of MMP at the basal level, the activation of caspase-3, and the cleavage of PARP, which is a substrate protein of activated caspase-3 (41) in V79-4 cells. These results indicate that the ability of morin to attenuate oxidative stress was partly dependent on inhibition of mitochondrial-related apoptosis.

Previous evidence strongly suggests that the Nrf2-mediated signaling pathway is essential in protecting cells against oxidative stress. Nrf2, a basic leucine zipper transcription factor, plays an important role in the transcriptional regulation of phase II enzymes by binding to AREs $(44,45)$. Under basal conditions, Nrf2-dependent transcription is suppressed by Keap1, a negative regulator of Nrf2, which facilitates the degradation of Nrf2 through ubiquitin-mediated proteasomal degradation $(45,48)$. Upon the modification of specific thiols by insult, Keap1 triggers the dissociation of Nrf2 from the Nrf2-Keap1 complex in the cytoplasm and allows Nrf2 to translocate into the nucleus, where it subsequently activates the AREs present in the promoter regions of an array of genes $(44,48)$. Moreover, several previous studies have found that the phosphorylation of Nrf2 (Try568) led to the nuclear export of Nrf2 $(49,50)$. Therefore, we investigated the Nrf2 pathway to determine whether it contributes to the protective effects of morin against $\mathrm{H}_{2} \mathrm{O}_{2}$-induced oxidative stress. In the present study, our results strongly support the ability of morin to stimulate the Nrf2 pathway; morin treatment increased Nrf2 accumulation and phosphorylation and decreased Keap1 expression in a time-dependent manner. Following the treatment of V79-4 cells with morin, we also observed significant increases in HO-1 expression and activity, while NQO1 was unaffected by the morin treatment. HO-1 is an Nrf2 downstream target and a powerful indirect antioxidant enzyme, which is a rate-limiting enzyme in heme catabolism. This enzyme converts heme to beneficial byproducts such as carbon monoxide and bilirubin, which can directly scavenge free radicals and repair DNA damage caused by oxidative 
stress (48). However, pretreatment with ZnPP, an inhibitor of HO-1, markedly abrogated the protective effects of morin against $\mathrm{H}_{2} \mathrm{O}_{2}$-induced MMP loss and inhibition of the growth of the V79-4 cells (Fig. 7). Therefore, our results support the supposition that the cytoprotective effect of morin against oxidative stress in V79-4 cells is mediated through activation of the Nrf2/HO-1 signaling pathway.

In conclusion, the present study provides evidence that morin protects lung fibroblast V79-4 cells from oxidative stress-induced DNA damage and cell death via the suppression of ROS generation and mitochondrial dysfunction. This process is also associated with the involvement of Nrf2 activation and the upregulation of the expression of its downstream antioxidant gene HO-1 in order to protect cells from oxidative stress. Therefore, morin may be of therapeutic value in the prevention and treatment of various human diseases associated with oxidative stress.

\section{Acknowledgements}

This study was supported by the Functional Districts of the Science Belt Support Program, Ministry of Science, ICT and Future Planning and Basic Science Research Program through a grant from the National Research Foundation of Korea (NRF) funded by the Korea government (no. 2015R1A2A2A01004633).

\section{References}

1. Dröge W: Free radicals in the physiological control of cell function. Physiol Rev 82: 47-95, 2002.

2. Lyakhovich A and Graifer D: Mitochondria-mediated oxidative stress: Old Target for New drugs. Curr Med Chem 22: 3040-3053, 2015.

3. Ermakov AV, Konkova MS, Kostyuk SV, Izevskaya VL, Baranova A and Veiko NN: Oxidized extracellular DNA as a stress signal in human cells. Oxid Med Cell Longev 2013: 649747, 2013.

4. Yang HY and Lee TH: Antioxidant enzymes as redox-based biomarkers: A brief review. BMB Rep 48: 200-208, 2015.

5. Alfadda AA and Sallam RM: Reactive oxygen species in health and disease. J Biomed Biotechnol 2012: 936486, 2012.

6. Cha MY, Kim DK and Mook-Jung I: The role of mitochondrial DNA mutation on neurodegenerative diseases. Exp Mol Med 47: e150, 2015.

7. Ginter E, Simko V and Panakova V: Antioxidants in health and disease. Bratisl Lek Listy 115: 603-606, 2014.

8. Cirillo G, Curcio M, Vittorio O, Iemma F, Restuccia D, Spizzirri UG, Puoci F and Picci N: Polyphenol conjugates and human health: A perspective review. Crit Rev Food Sci Nutr 56: 326-337, 2016.

9. Landete JM: Dietary intake of natural antioxidants: Vitamins and polyphenols. Crit Rev Food Sci Nutr 53: 706-721, 2013.

10. Kehrer JP and Klotz LO: Free radicals and related reactive species as mediators of tissue injury and disease: Implications for Health. Crit Rev Toxicol 45: 765-798, 2015.

11. Kancheva VD and Kasaikina OT: Bio-antioxidants - a chemical base of their antioxidant activity and beneficial effect on human health. Curr Med Chem 20: 4784-4805, 2013.

12. Bondonno $\mathrm{CP}$, Croft $\mathrm{KD}$, Ward $\mathrm{N}$, Considine $\mathrm{MJ}$ and Hodgson JM: Dietary flavonoids and nitrate: Effects on nitric oxide and vascular function. Nutr Rev 73: 216-235, 2015.

13. Stockert JC, Colman OD and Cañete M: Fluorescence reaction of leukocyte granules by morin. Acta Histochem Suppl 31: 243-252, 1985.

14. Srinivas NR: Recent trends in preclinical drug-drug interaction studies of flavonoids - Review of case studies, issues and perspectives. Phytother Res 29: 1679-1691, 2015.

15. Caselli A, Cirri P, Santi A and Paoli P: Morin: A Promising natural drug. Curr Med Chem 23: 774-791, 2016.
16. Kim JM, Lee EK, Park G, Kim MK, Yokozawa T, Yu BP and Chung HY: Morin modulates the oxidative stress-induced NF-kappaB pathway through its anti-oxidant activity. Free Radic Res 44: 454-461, 2010.

17. Komirishetty P, Areti A, Sistla R and Kumar A: Morin mitigates chronic constriction injury (CCI)-induced peripheral neuropathy by inhibiting oxidative stress induced PARP over-activation and neuroinflammation. Neurochem Res 41: 2029-2042, 2016.

18. Ola MS, Aleisa AM, Al-Rejaie SS, Abuohashish HM, Parmar MY, Alhomida AS and Ahmed MM: Flavonoid, morin inhibits oxidative stress, inflammation and enhances neurotrophic support in the brain of streptozotocin-induced diabetic rats. Neurol Sci 35: 1003-1008, 2014.

19. MadanKumar P, NaveenKumar P, Manikandan S, Devaraj H and NiranjaliDevaraj S: Morin ameliorates chemically induced liver fibrosis in vivo and inhibits stellate cell proliferation in vitro by suppressing Wnt $/ \beta$-catenin signaling. Toxicol Appl Pharmacol 277: 210-220, 2014.

20. Ganguli A, Das A, Nag D, Bhattacharya S and Chakrabarti G: Potential role of autophagy in smokeless tobacco extract-induced cytotoxicity and in morin-induced protection in oral epithelial cells. Food Chem Toxicol 90: 160-170, 2016.

21. Paoli P, Cirri P, Caselli A, Ranaldi F, Bruschi G, Santi A and Camici G: The insulin-mimetic effect of Morin: A promising molecule in diabetes treatment. Biochim Biophys Acta 1830: 3102-3111, 2013.

22. Sendrayaperumal V, Iyyam Pillai S and Subramanian S: Design, synthesis and characterization of zinc-morin, a metal flavonol complex and evaluation of its antidiabetic potential in HFD-STZ induced type 2 diabetes in rats. Chem Biol Interact 219: 9-17, 2014.

23. Qureshi AA, Guan XQ, Reis JC, Papasian CJ, Jabre S, Morrison DC and Qureshi N: Inhibition of nitric oxide and inflammatory cytokines in LPS-stimulated murine macrophages by resveratrol, a potent proteasome inhibitor. Lipids Health Dis 11: 76, 2012.

24. Dhanasekar C, Kalaiselvan S and Rasool M: Morin, a bioflavonoid suppresses monosodium urate crystal-induced inflammatory immune response in RAW 264.7 macrophages through the inhibition of inflammatory mediators, intracellular ROS levels and NF- $\kappa$ B activation. PLoS One 10: e0145093, 2015.

25. Dilshara MG, Jayasooriya RG, Lee S, Choi YH and Kim GY: Morin downregulates nitric oxide and prostaglandin $E_{2}$ production in LPS-stimulated BV2 microglial cells by suppressing NF- $\kappa \mathrm{B}$ activity and activating HO-1 induction. Environ Toxicol Pharmacol 44: 62-68, 2016.

26. Gupta SC, Phromnoi K and Aggarwal BB: Morin inhibits STAT3 tyrosine 705 phosphorylation in tumor cells through activation of protein tyrosine phosphatase SHP1. Biochem Pharmacol 85: 898-912, 2013.

27. Manna SK, Aggarwal RS, Sethi G, Aggarwal BB and Ramesh GT: Morin (3,5,7,2',4'-pentahydroxyflavone) abolishes nuclear factor-kappaB activation induced by various carcinogens and inflammatory stimuli, leading to suppression of nuclear factor-kappaB-regulated gene expression and up-regulation of apoptosis. Clin Cancer Res 13: 2290-2297, 2007.

28. Park C, Lee WS, Go SI, Nagappan A, Han MH, Hong SH, Kim GS, Kim GY, Kwon TK, Ryu CH, et al: Morin, a flavonoid from Moraceae, induces apoptosis by induction of BAD protein in human leukemic cells. Int J Mol Sci 16: 645-659, 2014.

29. Hyun HB, Lee WS, Go SI, Nagappan A, Park C, Han MH, Hong SH, Kim G, Kim GY, Cheong J, et al: The flavonoid morin from Moraceae induces apoptosis by modulation of Bcl-2 family members and Fas receptor in HCT 116 cells. Int J Oncol 46: 2670-2678, 2015

30. Park JY, Kang KA, Kim KC, Cha JW, Kim EH and Hyun JW: Morin induces heme oxygenase-1 via ERK-Nrf2 signaling pathway. J Cancer Prev 18: 249-256, 2013.

31. Rizvi F, Mathur A and Kakkar P: Morin mitigates acetaminophen-induced liver injury by potentiating Nrf2 regulated survival mechanism through molecular intervention in PHLPP2-Akt-Gsk3ß axis. Apoptosis 20: 1296-1306, 2015.

32. Mathur A, Rizvi F and Kakkar P: PHLPP2 down regulation influences nuclear Nrf 2 stability via Akt-1/Gsk3//Fyn kinase axis in acetaminophen induced oxidative renal toxicity: Protection accorded by morin. Food Chem Toxicol 89: 19-31, 2016.

33. Lee YJ, Koh EK, Kim JE, Go J, Song SH, Seong JE, Son HJ, Kang BC and Hwang DY: Beneficial effects of ethanol extracts of Red Liriope platyphylla on vascular dysfunction in the aorta of spontaneously hypertensive rats. Lab Anim Res 31: 13-23, 2015. 
34. Sreejayan $\mathrm{N}$ and Rao MN: Nitric oxide scavenging by curcuminoids. J Pharm Pharmacol 49: 105-107, 1997.

35. Kim SH, Kang SH and Kang BS: Therapeutic effects of dihydroartemisinin and transferrin against glioblastoma. Nutr Res Pract 10: 393-397, 2016.

36. Eom SA, Kim DW, Shin MJ, Ahn EH, Chung SY, Sohn EJ, Jo HS, Jeon SJ, Kim DS, Kwon HY, et al: Protective effects of PEP-1-Catalase on stress-induced cellular toxicity and MPTP-induced Parkinson's disease. BMB Rep 48: 395-400, 2015

37. Chun SK, Go K, Yang MJ, Zendejas I, Behrns KE and Kim JS: Autophagy in ischemic livers: A critical role of Sirtuin 1/Mitofusin 2 axis in autophagy induction. Toxicol Res 32: 35-46, 2016.

38. Alaoui-Jamali MA, BismarTA, Gupta A, Szarek WA, Su J, Song W, $\mathrm{Xu}$ Y, Xu B, Liu G, Vlahakis JZ, et al: A novel experimental heme oxygenase-1-targeted therapy for hormone-refractory prostate cancer. Cancer Res 69: 8017-8024, 2009.

39. Hensley P, Mishra M and Kyprianou N: Targeting caspases in cancer therapeutics. Biol Chem 394: 831-843, 2013.

40. MacKenzie SH and Clark AC: Targeting cell death in tumors by activating caspases. Curr Cancer Drug Targets 8: 98-109, 2008.

41. Lazebnik YA, Kaufmann SH, Desnoyers S, Poirier GG and Earnshaw WC: Cleavage of poly(ADP-ribose) polymerase by a proteinase with properties like ICE. Nature 371: 346-347, 1994.

42. Azqueta A, Slyskova J, Langie SA, O'Neill Gaivão I and Collins A: Comet assay to measure DNA repair: Approach and applications. Front Genet 5: 288, 2014.
43. Rogakou EP, Pilch DR, Orr AH, Ivanova VS and Bonner WM: DNA double-stranded breaks induce histone $\mathrm{H} 2 \mathrm{AX}$ phosphorylation on serine 139. J Biol Chem 273: 5858-5868, 1998.

44. Dinkova-Kostova AT, Holtzclaw WD, Cole RN, Itoh K, Wakabayashi N, Katoh Y, Yamamoto M and Talalay P: Direct evidence that sulfhydryl groups of Keap1 are the sensors regulating induction of phase 2 enzymes that protect against carcinogens and oxidants. Proc Natl Acad Sci USA 99: 11908-11913, 2002.

45. Gan L and Johnson JA: Oxidative damage and the Nrf2-ARE pathway in neurodegenerative diseases. Biochim Biophys Acta 1842: 1208-1218, 2014.

46. Wang Y, Yang J and Yi J: Redox sensing by proteins: Oxidative modifications on cysteines and the consequent events. Antioxid Redox Signal 16: 649-657, 2012.

47. Clerkin JS, Naughton R, Quiney C and Cotter TG: Mechanisms of ROS modulated cell survival during carcinogenesis. Cancer Lett 266: 30-36, 2008

48. Jaramillo MC and Zhang DD: The emerging role of the Nrf2-Keap1 signaling pathway in cancer. Genes Dev 27: 2179-2191, 2013.

49. Kaspar JW and Jaiswal AK: Tyrosine phosphorylation controls nuclear export of Fyn, allowing Nrf2 activation of cytoprotective gene expression. FASEB J 25: 1076-1087, 2011.

50. Jain AK and Jaiswal AK: Phosphorylation of tyrosine 568 controls nuclear export of Nrf2. J Biol Chem 281: 12132-12142, 2006. 